\title{
Why Trieste matters
}

\section{S. P. Sashidharan}

Trieste mental health service is considered as one of the best mental healthcare systems in the world. This service is now under threat from right-wing politicians in the local region. We argue that this is a threat to progressive community psychiatry beyond Trieste and Italy. It is important for us to join forces with international colleagues and organisations in the campaign to defend and preserve the current service model in Trieste.

\section{Keywords}

Community mental health; community mental health teams; mental health service; political threat to mental health services; best models of practice.

\section{Copyright and usage}

(C) The Author(s), 2021. Published by Cambridge University Press on behalf of the Royal College of Psychiatrists.
S. P. Sashidharan is an Honorary Professor in the Institute of Health \& Wellbeing University of Glasgow and a psychiatrist based in Glasgow, Scotland.

What does a good mental health system look like? Where do mental health services accord with expert views and expectations (of both professionals and people with lived experience) of humane, person-centred and effective mental healthcare? Is it possible to deliver mental healthcare that meets commonly agreed and internationally recognised standards? The answer to all these questions is Trieste - a model of psychiatric services that has provided an important, global reference point of good and effective care for over 40 years. ${ }^{1}$

\section{Guiding principles of care}

The historical development of the community mental health system in Trieste is well-known. The current service in Trieste is the product of cultural and political movements that centred around the plight of people who are mentally ill and successful de-institutionalisation over the past 50 years. Psychiatric practice in Trieste is based on three guiding principles: holistic care that focuses on the whole person rather than the disease; an ecological approach that addresses the context, the network and the social groups of patients; and a rights-based approach ensuring that civil rights of people with psychiatric problems, both legal and social rights; for example open doors, avoiding restrictive care, the right to socially meaningful work are at the forefront of care. This means ready access to care and treatment not limited by particular diagnoses, severity thresholds or other exclusion criteria, very low use of inpatient care, service flexibility and mobility, involvement of multiple comprehensive resources, such as a wide range of welfare provisions in the therapeutic and support programmes, and continuity instead of transitions in care.

There are no locked doors anywhere and Trieste has one of the lowest rates of involuntary admissions in any high-income country. The community services work very closely with families, ensure respect for patients and their social system, support them to be a citizen and ensure access to proper work and independent living. The service for a population of 240000 people is provided through four $24 / 7$ open community mental health centres (each with 6 beds and a team of 26 staff, including psychiatrists), 6 beds in a general hospital and 45 supported housing placements. It is an integrated-care model ensuring care and support for every citizen with mental health needs in Trieste. $^{2}$

\section{The threat}

This is now under threat. Experts, service users and families are increasingly concerned that right-wing politicians in the region are seeking to dismantle the current services in Trieste, despite it being one of the most celebrated and progressive mental healthcare systems in the world. ${ }^{3}$ An international campaign to save Trieste is underway. ${ }^{4}$ Psychiatrists, professional bodies and all those who support progressive mental healthcare across the world should recognise this is a critical moment in the history of community and progressive psychiatry. We must defend and preserve what is best in mental healthcare and reject the political, ideologically driven attempt to dismantle Trieste and turn the clock back.

What is happening in Trieste is well documented by our colleagues in Italy and the national media. The threat to mental health services in Trieste derives from a political ideology: viewing current mental health services as an unwelcome legacy of left-wing politics, a dogma that government health services should be privatised and a desire to cut costs.

In 2018 the local government changed in the region of Friuli Venezia Giulia, with the election of far-right parties assuming power. Almost immediately 'a war' against Trieste was announced, in which community-based mental health services were targeted for cutbacks or closure. Financial cuts to mental healthcare following coronavirus disease 2019 (COVID-19) and the retirement of the director of Trieste services have triggered the current crisis. The appointment of a new head of service has been rushed through, with little consultation and no regard for local considerations. Regional political leaders of right-wing parties have repeatedly made clear their intention to reverse the current model of care, abandon the values and ethical foundation underpinning the Trieste system, and undo the progressive reforms there.

The humanistic approach that characterises Trieste is regarded as an 'ancient vision' requiring change. As Roberto Mezzina, the former director of mental health services, warns 'the regional government's objective is to reduce or abolish the community mental health centres under the pretence of their right-wing ideology and Covid-19 cutbacks. This is about bringing back the old system of hospital beds, long-term residential facilities and outpatient visits based on medication. This has nothing to do with cost or benefiting people with mental illness, but everything to do with ideology and creating a favourable environment for speculation and private capital'. 


\section{A lesson from the USA}

This short-sighted, penny wise/pound foolish approach ignores the painful lessons of history. With the passage of the Kennedy Community Mental Health Centers Act in 1963, the USA briefly enjoyed the best system of community psychiatry in the world. This was defunded and destroyed in 1980 by the right-wing Reagan administration and their belief in 'small government'. The money saved from closing hospitals, originally earmarked for new community-based treatment services and decent community housing, was instead diverted to tax relief or the support of other programmes. Community centres either closed or went private and would no longer accept patients who were severely ill, who were disadvantaged economically and expensive to treat. As a result, psychiatric emergency rooms were routinely inundated and the process of de-institutionalisation became one of re-institutionalisation, with older patients ending up in nursing homes and younger ones confined in prisons. Hundreds of thousands of people with mental illness fell through the cracks and became chronically homeless. We can see the results today - in the erosion of mental health infrastructure and hundreds of thousands of people with severe mental illness languishing in prisons or rendered homeless, while psychiatric care once again becomes ossified within narrow medical approaches.

\section{Conclusions}

Trieste is an exemplar service that has had a profound influence and impact across the world, including the UK. We should take note of what is unfolding, as the current threat to Trieste has much wider implications than what is happening in one small corner of Italy. What is happening in Trieste is a threat to all decent, effective, humane services in mental healthcare everywhere in the world. This is not about the ups and downs of local politics or the fate of one service. What is at stake are the hard-won gains of community mental health, improvements in patient care and a rights-based person-centred approach in caring for, treating and supporting the most vulnerable people in our society. If one of the best mental health systems in the world ${ }^{5}$ can be dismantled with such impunity and on a political whim, similar services across the world are also at risk.

Those of us who are committed to a vision of progressive mental healthcare must resist the regression and vandalism of Trieste services by joining forces with our international colleagues and professional bodies such as the World Psychiatric Association, the World Federation for Mental Health and international organisations such as the World Health Organization. We cannot remain silent.

S. P. Sashidharan (D), MRCPsych, PhD, Honorary Professor, Institute of Health \& Wellbeing, University of Glasgow, UK

Correspondence: S. P. Sashidharan. Email: s.p.sashidharan@gmail.com

First received 29 Jun 2021, final revision 13 Aug 2021, accepted 8 Sep 2021

Funding

None.

\section{Declaration of interest}

None.

\section{References}

1 Walters R. The old asylum is gone: today a mental health system serves all. Health Aff 2020; 39: 186-91.

2 Mezzina R. Community mental healthcare in Trieste and beyond. an 'open door-no restraint' system of care for recovery and citizenship. J Nerv Ment Dis 2014; 202: 440-5.

3 Day M. Trieste's mental healthcare model is under threat, claim supporters of the community-based approach. BMJ 2021; 373: n1597.

4 Smith M. 'An unfolding nightmare': Trieste's pioneering mental health system under threat, say campaigners. The Independent 22 Jun 2021 (https://www. independent.co.uk/independentpremium/world/trieste-mental-health-italypolitics-b1870595.html).

5 World Health Organization. Guidance on Community Mental Health Services: Promoting Person-Centred and Rights-Based Approaches. WHO, 2021 (https:// www.who.int/publications/i/item/9789240025707) 